\title{
EL POSICIONAMIENTO DE LA REVISTA EL RENACIMIENTO (1847) EN EL DEBATE ARQUITECTÓNICO ENTRE CLASICISMO Y ROMANTICISMO EN LA ESPAÑA ISABELINA
}

\author{
The Positioning of the Magazine El Renacimiento (1847) in the Architectural \\ Debate between Classicism and Romanticism in the Spain of Isabel II
}

\author{
María Victoria Álvarez Rodríguez \\ mvalvarez@usal.es \\ Universidad de Salamanca. España \\ Fecha de recepción: 14/12/2016 \\ Fecha de aceptación: 28/02/2017
}

RESUMEN: La Europa decimonónica asistió al surgimiento de una de las aportaciones más novedosas y originales al campo de la historiografía artística contemporánea: las publicaciones periódicas en las que se abordaba el estudio de las Bellas Artes desde una perspectiva bastante alejada de la seriedad característica de las academias. El caso español no fue una excepción en este sentido, aunque hubo que esperar hasta el reinado de Isabel II (1806-1878) para que la recién conquistada libertad de prensa permitiera la aparición de publicaciones de este tipo. En algunos casos estaban estrechamente relacionadas con la defensa de los ideales románticos, mientras que en otros tenían como finalidad servir de entretenimiento al gran público sin comprometerse con ninguna ideología. Y entre las más interesantes que vieron la luz durante el reinado isabelino, El Renacimiento (1847) posee una especial relevancia tanto por su preciosismo como por la seriedad con la que trató la cuestión artística. En el presente estudio nos centraremos en el análisis de los artículos publicados en ella sobre el debate entre clasicismo y romanticismo que estaba teniendo lugar en España por aquel entonces, comparando las opiniones de sus redactores a este respecto y las razones por las cuales poseían posicionamientos ciertamente diferentes.

Palabras clave: Prensa artística; Historiografía artística; Siglo xix; Arquitectura; España.

ABSTRACT: 19th century Europe saw the emergence of one of the most originals contributions to the field of the contemporary art historiography: the magazines in which the study of Fine Arts was addressed 
from a quite far perspective from the characteristic seriousness of the academies. The Spanish case was no exception in this regard, although it had to wait until the reign of Isabel II (1806-1878) for the newly won freedom of the press allowed the emergence of such publications. In some cases they were closely related to the defense of romantic ideals, while others were intended to serve as entertainment to the general public without committing to any ideology. Among the most interesting magazines that saw the light during the reign of Isabel II, El Renacimiento (1847) has a special significance for its preciousness and the seriousness with which tried the artistic question. In this study we will focus on the analysis of articles published in it on the debate between classicism and romanticism that was taking place in Spain at the time, comparing the views of their authors in this regard and the reasons for their different positionings.

Keywords: Art press; Art historiography; 19th century; Architecture; Spain.

SUMARIO: 1. Introducción. 2. Surgimiento y evolución de las revistas artísticas isabelinas. 3. El Renacimiento (1847). 3.1. Federico de Madrazo (1815-1894) y Eugenio de Ochoa (1815-1872). 3.2. Pedro de Madrazo (1816-1898). 3.3. Antonio de Zabaleta (1803-1864). 3.4. Francesc Pi i Margall (18241901). 4. Conclusiones. 5. Referencias bibliográficas.

\section{INTRODUCCIÓN}

En el transcurso del siglo xIx la historiografía artística internacional experimentó una evolución considerable como consecuencia de la proliferación de publicaciones periódicas en las que se abordaba, de manera más o menos científica, el estudio de las Bellas Artes. Gracias a la progresiva democratización de la cultura que se llevó a cabo durante dicha centuria, esos estudios comenzaron a abandonar poco a poco el ámbito académico para pasar a ser de dominio público, si bien es necesario establecer una diferencia entre aquellas revistas en las que el arte era tratado con la misma ligereza que la literatura, el teatro, la música y las noticias de sociedad y aquellas en las que, por el contrario, un equipo de especialistas en la materia (historiadores, historiadores del arte y arqueólogos) intentaba ofrecer a sus lectores un discurso más sesudo y científico. A esto debemos sumar las revistas de corte más profesional dirigidas a un colectivo de arquitectos, herederas de las feuilles d'annonces francesas y en las que, por lo general, se hacía más hincapié en cuestiones técnicas relacionadas con la praxis arquitectónica que en disquisiciones histórico-artísticas (Isac, 1987, pp. 111-112).

Esta democratización de la cultura a la que nos referimos no puede desligarse de las sucesivas libertades de prensa alcanzadas en la España decimonónica. Si bien en época de Fernando VII (1784-1833) había existido una desconexión casi absoluta con lo que se estaba llevando a cabo en los círculos culturales extranjeros, ya que el monarca consideraba que cualquier idea procedente de más allá de los Pirineos podía suponer una amenaza a su gobierno, con la regencia de su viuda María Cristina de Borbón-Dos Sicilias (1806-1878) y, sobre todo, con la llegada al trono de su hija Isabel II (1830-1904), comenzaron a realizarse avances sin los cuales habría sido imposible que el país hubiera seguido la senda abierta por Francia en cuanto a la evolución de las revistas artísticas. Sirvan como ejemplo de dichos 
avances la aprobación de medidas como la Ley de Prensa de 1837 y la Ley Nocedal de 1857 , que permitieron la publicación de un abanico cada vez más amplio de títulos entre los cuales las Bellas Artes gozaron de un gran interés desde el primer momento (Blanco Martín, 1987, p. 43). Y entre esas revistas, El Renacimiento (1847) constituye uno de los ejemplos más interesantes tanto en cuanto a su formato como en cuanto a su contenido, distinguiéndose notablemente, como veremos en las siguientes páginas, de otras publicaciones de la década de 1840 por conceder una considerable importancia a la situación que estaba atravesando entonces la arquitectura española (Henares y Calatrava, 1982).

En esos debates tan comunes durante el reinado isabelino, girando en torno a la cuestión clasicismo-romanticismo como una inevitable consecuencia de la coexistencia de las mentalidades conservadora y liberal, El Renacimiento publicó algunos artículos que demuestran que en el propio rotativo estaba presente la misma dualidad, puesto que algunos de sus redactores se decantaron por los presupuestos clasicistas mientras que otros no dudaron en romper públicamente una lanza por la apertura a los historicismos.

\section{SURGIMIENTO Y EVOLUCIÓN DE LAS REVISTAS ARTÍSTICAS ISABELINAS}

Unas breves líneas para explicar cómo se produjo el desarrollo de estos rotativos y las etapas que se pueden observar en su evolución, estrechamente relacionada con los cambios culturales que tuvieron lugar en España entre 1833 y 1868 coincidiendo con el reinado de Isabel II. Un examen minucioso de las principales publicaciones que vieron la luz en estas coordenadas cronológicas pone de manifiesto la existencia de tres tipos de revistas, todas imbuidas de la mentalidad romántica en mayor o menor medida, pero con cambios notables en cuanto a su manera de abordar el estudio de las Bellas Artes.

La primera etapa corresponde a la década de 1830, los primeros años del reinado isabelino, y la principal característica de las revistas publicadas en esos años es el profundo compromiso que poseían con el Romanticismo. Dirigidas por lo general por colectivos de jóvenes artistas deseosos de dar a conocer en España los presupuestos que desde hacía años estaban triunfando al otro lado de los Pirineos, solían centrarse en el arte y la literatura y estaban destinadas a un público compuesto también por artistas, lo que a la postre acabó conduciéndolas a la ruina dado que su exiguo número de lectores no bastaba para costear los gastos de la empresa. En esta etapa encontraríamos revistas tan conocidas como El Artista, publicada entre 1835 y 1836 y de la que hablaremos más adelante, con aportaciones tan paradigmáticas del Romanticismo español como el poema La canción del pirata de José de Espronceda (1808-1842), o No Me Olvides, publicada entre 1837 y 1838 por otro poeta romántico, Jacinto de Salas y Quiroga (1813-1849). 
Más adelante, en las décadas de 1840 y 1850, asistimos al florecimiento en España de un tipo diferente de revista que también contaba con exitosos precedentes en países extranjeros. En esta etapa alcanzaron un enorme éxito las publicaciones de carácter más enciclopédico que las de la década anterior, rotativos que ya no estaban dirigidos a un colectivo de artistas, sino que, a fin de contar con un elevado número de lectores, tenían como meta servir de entretenimiento a toda la familia mediante una personalidad más divulgativa y burguesa. Su implicación con la doctrina romántica era, por tanto, mucho menor que los ejemplos de 1830 que hemos citado, aunque eso no les impidiera mostrar su cercanía a esta mentalidad una vez se hubo afianzado en nuestro país; sirvan como ejemplo los artículos dedicados en sus páginas a las Bellas Artes, al lado de otros sobre temas tan variados como la historia, la botánica, la gastronomía, las ciencias, en los que a menudo se hacía hincapié en la importancia de conservar y restaurar los monumentos patrios en aras del creciente interés por lo nacional, lo local y lo pintoresco. Entre los ejemplos más conocidos de este tipo de revista la protagonista absoluta fue Semanario Pintoresco Español (1836), que realmente fue una pionera por haber surgido en la etapa anterior y que sirvió como modelo de inspiración a todas las que la siguieron, como fue el caso de Museo de las Familias (1843-1870), El Laberinto (1843-1845), etc. También encontramos en esta etapa el caso concreto de El Renacimiento (1847), la revista en la que hemos decidido centrar nuestro estudio, que se apartó de la tónica más habitual en dicha época por poseer una personalidad decididamente más artística que divulgativa.

Finalmente, en la década de 1860 que presenció la caída de Isabel II a causa de la Revolución Gloriosa de 1868 se dio una tercera etapa en la que arraigó un prototipo muy distinto de revista. Como consecuencia de la mentalidad cada vez más positivista que se estaba dejando sentir en los círculos culturales de la nación, las publicaciones dedicadas en esos años a las Bellas Artes abordaban su estudio de una manera mucho más sesuda, meditada y científica, prescindiendo de la exaltación romántica propia de las de la primera etapa y del carácter más ligero y poliédrico de las de la segunda. En esta década los artículos sobre cuestiones artísticas dejan de ser redactados por simples diletantes para contar en cambio con la rúbrica de historiadores, historiadores del arte y arqueólogos, personajes que siempre solían dedicarse profesionalmente a su estudio y que por lo tanto dotaban a sus disquisiciones de una seriedad hasta entonces muy poco frecuente en estos rotativos. Esto se encuentra presente en publicaciones como El Arte en España (1862-1870), El Arte (1866) o La Revista de Bellas Artes (1866-1868), en las que la diversidad temática acabó siendo sustituida por una especialización indiscutible.

A raíz de lo que acabamos de analizar, salta a la vista que las revistas artísticas de la época isabelina fueron en todo momento absolutamente permeables a los cambios que hemos dicho que se produjeron en España en el ámbito cultural. El Romanticismo más exaltado de los primeros años, recién llegado de Francia por los jóvenes que habían estado viviendo allí o por los exiliados que regresaban al país, 
dio paso a una variante más moderada de este movimiento que prefería poner el acento en lo pintoresco antes que en lo pasional, para devenir finalmente en un posicionamiento más positivista que concedió a estos rotativos una mayor seriedad en las postrimerías del reinado isabelino.

\section{EL RENACIMIENTO (1847)}

Como hemos dicho, esta publicación constituye una rara avis entre las que vieron la luz en las décadas de 1840 y 1850 por pertenecer al tipo de revista que había sido más común en la de 1830 , la consagrada por entero a cuestiones artísticas, dirigida por un grupo de artistas y dedicada, a su vez, a un público potencial compuesto por artistas. La razón de ser de esto es sencilla: a pesar de pertenecer a un momento más avanzado en la evolución de la prensa artística isabelina, la personalidad de El Renacimiento seguía anclada en el pasado por ser la heredera directa de El Artista, fundada en 1835 por el pintor Federico de Madrazo (1815-1894) y el escritor Eugenio de Ochoa (1815-1872) (Calvo Serraller y González García, 1981, p. 17).

Efectivamente, esta revista fue considerada una pionera entre las que vieron la luz a comienzos del reinado isabelino con la vocación de convertirse en tribunas desde las cuales dar a conocer los presupuestos del Romanticismo, al igual que sucedió en los siguientes años con otras como EI Siglo XIX (1837-1838), No Me Olvides (1837-1838), etc. Fue también la primera en su género que tomó como inspiración a una francesa, su homóloga L'Artiste, journal de la littérature et des beaux-arts, fundada en 1831 por el pintor Achille Ricourt (1797-1879) (García Melero, 2002, p. 171). Esta dependencia con respecto al extranjero, que explica en gran medida el posicionamiento romántico de El Artista especialmente en cuanto a lo literario, no resulta extraña si tenemos en cuenta que tanto Madrazo como Ochoa habían tenido la oportunidad de conocer de primera mano los presupuestos de dicho movimiento en París. En los años anteriores a la fundación del rotativo Madrazo había disfrutado de una estancia formativa en la capital francesa para estudiar pintura (Lafuente Ferrari, 1987, p. 489) mientras que Ochoa había estado asistiendo a la École des Beaux-Arts antes de tener que abandonar sus estudios debido a una enfermedad (Torres Nebrera, 2012, pp. 241-243). Aunque El Artista no tuvo más éxito que las revistas románticas que salieron a la calle por aquel entonces, debido sobre todo a que al estar dirigidas a ese público minoritario compuesto por artistas no podían hacer frente a los gastos derivados de la publicación, lo cierto es que consiguió cumplir con el que había sido su principal objetivo: convertirse en una tribuna artística, literaria y cultural desde la cual pudieran darse a conocer en España las inquietudes de una nueva generación que hasta entonces no había poseído un órgano de representación (Ayala Aracil, 2002, p. 35; López Sanz, 2000). 
Ahora bien, cuando Madrazo y Ochoa volvieron a reunirse en 1847 para ponerse de nuevo al frente de una revista, once años después del cierre de El Artista, el espíritu que la animaba era notablemente distinto del que había caracterizado a su predecesora, una cuestión en la que nos parece importante hacer hincapié porque condicionó de un modo decisivo el ideario de El Renacimiento y, en última instancia, su posicionamiento con respecto a las Bellas Artes. Hay que tener en cuenta que ambos directores habían dejado de ser unas jóvenes promesas para convertirse en dos artistas de reconocido e incuestionable prestigio en el Madrid isabelino: mientras que Madrazo había llegado a ser nombrado pintor de cámara de la Casa Real y director del Museo del Prado, Ochoa ostentaba los cargos de consejero de Estado y académico de la Lengua (Rodríguez Gutiérrez, 2014, p. 77). Resulta fácil de entender por qué ambos quisieron dejar claro en el primer número de El Renacimiento que los excesos románticos de la publicación anterior, que achacaban condescendientes a la exaltación de la juventud, habían dado paso a un carácter mucho más reposado y ecuánime pese a que muchas de sus características siguieran estando presentes, como las inquietudes artísticas del equipo directivo y el preciosismo en cuanto a su formato.

Pero ¿cuál fue realmente el motivo de que Madrazo y Ochoa quisieran sujetar de nuevo las riendas de una revista que, como demostraría el paso del tiempo, volvería a ser una iniciativa fugaz que solo duraría unos meses? La explicación la encontramos en la introducción de ese primer número de El Renacimiento aparecido el 14 de marzo de 1847, en el que sus directores explicaban que la publicación había sido concebida como "la continuación de El Artista, nombre al que, por motivos que no son del caso, ha debido renunciar, sustituyéndose con el nuevo y significativo título de El Renacimiento" (Madrazo y Ochoa, 14 de marzo de 1847, p. 3). Con esto aludían a la indignación que les había causado que un grupo de escritores que no tenían nada que ver con ellos se atrevieran a apoderarse del nombre de El Artista, así como de su prestigio, para fundar otra revista que además pretendía competir con lo que habían realizado ellos diez años antes. Contamos con un testimonio especialmente significativo en una carta del escritor, diplomático y político Juan Valera (1824-1905) a su padre, en la que le informa de que en 1847 iba a aparecer una revista, cuyo nombre era El Artista, promovida por los mencionados autores. "La impresión será de un lujo extremo», aseguraba Valera, "y todo él saldrá del modo más primoroso, puesto que tiene la pretensión de competir con el antiguo del mismo nombre» (García Castañeda, 1979, p. 44). Ambas publicaciones, como hemos dicho, salieron a la luz el mismo año y fueron desde un principio feroces competidoras, aunque ninguna consiguió sobrevivir por cuestiones presupuestarias. En cuanto a la elección del nuevo título, en ese mismo texto Madrazo y Ochoa afirmaban que remitía al sentimiento que les había embargado al renunciar en 1836 a El Artista: "Como las artes y las letras después de la borrascosa noche de los siglos medios, tambien nuestro Artista, el hijo predilecto de nuestro amor y 
nuestras esperanzas, tendrá algun día su Renacimiento!» (Madrazo, 14 de marzo de 1847, p. 1).

Esa competencia entre las revistas no se dio solo en cuanto al contenido de sus artículos, sino también en lo relativo a su formato. Si el sucedáneo de El Artista podía jactarse de poseer "un lujo extremo» en cuanto a su impresión, El Renacimiento no se quedaba atrás. El papel que se empleó a lo largo de sus diecinueve entregas fue de una gran calidad, especialmente en las litografías sueltas salidas de la Imprenta de Alhambra y Compañía situada en el número 4 de la Calle del Burro; las ocho páginas de la revista propiamente dicha, por el contrario, lo hicieron de la Imprenta de la Viuda de Burgos. Al igual que El Artista de 1835, esta nueva publicación seguía un formato tradicional en 4으 con texto a dos columnas, de 310 milímetros de alto por 215 milímetros de ancho.

La periodicidad, semanal, también era la misma. Parece claro que para Ochoa y Madrazo el diseño y la calidad y cuidado de la edición fueron desde sus comienzos una prioridad, algo de lo que dejan constancia ciertos cambios que llevaron a cabo a partir de la tercera entrega como los motivos ornamentales en los bordes de página, la mayor ostentación en las líneas de separación de los textos... No en vano ambos habían dejado claro en la introducción con la que comenzaba el primer número de El Renacimiento que su deseo era convertirla, al igual que El Artista, en «una bella y lujosa tribuna, exclusivamente consagrada á que se proclamen desde ella las sanas doctrinas artísticas y literarias» (Madrazo, 14 de marzo de 1847, p. 1); es decir, en una obra de arte tanto en su contenido como en su continente.

Entre los artistas que se hicieron cargo de su apartado gráfico encontramos, como es lógico teniendo en cuenta lo que acabamos de señalar, a algunos que habían formado parte del equipo de la publicación anterior como el propio Madrazo, Carlos Luis de Ribera y Fieve (1815-1891) o Joaquín Espalter y Rull (1809-1880). Todos ellos fueron artistas que, lejos de destacar únicamente en el campo del grabado, contaban con una notable trayectoria como pintores, circunstancia destinada a aumentar nuevamente el preciosismo de la revista. Cabe destacar en este sentido la lámina que acompañaba a la primera entrega, "Las Bellas Artes. Plantas del santuario», en la que los derroches de raigambre gótica que se observaban en el frontispicio de El Artista fueron sustituidos por una composición mucho más clásica, ordenada y compartimentada. En ella se hacía referencia a las distintas artes que trataría la revista mediante alegorías femeninas que rodean a una que representa, por su parte, a la inspiración divina. Nos parece de especial importancia este detalle porque, como comprobaremos más adelante, la religiosidad fue uno de los principales postulados de El Renacimiento, siendo tanto Madrazo como Ochoa de la opinión de que el cristianismo había sido la piedra de toque que había hecho florecer a las artes europeas. Completan la composición tres medallones con los bustos de Rafael Sanzio (1483-1520), Dante Alighieri (1265-1321) y Wolfgang Amadeus Mozart (1756-1791), de nuevo aludiendo a la diversidad de manifestaciones artísticas que 
abordaría El Renacimiento, y otros cuatro situados en las esquinas con las fachadas de las catedrales de León, Burgos, Toledo y Sevilla trazadas por el arquitecto Antonio de Zabaleta (1803-1864), en cuyas contribuciones profundizaremos más tarde.

En lo concerniente a los redactores que colaboraron con la revista, encontramos además de nombres ya mentados como Federico de Madrazo, Eugenio de Ochoa y Antonio de Zabaleta a otros de renombre en el campo de las Bellas Artes y la Historia del Arte: el pintor Valentín Carderera (1796-1880), el historiador Manuel de Assas (1813-1880), los escritores Francisco Navarro Villoslada (1818-1895) y Juan de Ariza Palomar (1816-1876), el crítico Pedro de Madrazo (1816-1898), el político Francesc Pi i Margall (1824-1901)... Muchos hablaron en sus artículos de cuestiones artísticas tan dispares como la evolución de los estilos, las biografías de los principales pinceles españoles, la crítica de exposiciones que se estaban llevando a cabo, la situación de los pensionados españoles en Roma, los premios ganados por las jóvenes promesas, etc.

No obstante, pese a que todos compartían un profundo interés por las Bellas Artes, no puede decirse que sus opiniones, al menos en cuanto a la cuestión arquitectónica, fueran las mismas. Como analizaremos en las siguientes páginas, el posicionamiento de El Renacimiento a este respecto no era unívoco, pues aunque la revista poseía una mentalidad bastante conservadora, los autores que se ocuparon de esta cuestión (en concreto Federico de Madrazo, Eugenio de Ochoa, Pedro de Madrazo, Antonio de Zabaleta y Francesc Pi i Margall) tenían sus propias ideas y no dudaron en defenderlas con vehemencia, mostrando en consecuencia en El Renacimiento la misma diversidad de opiniones que existía por entonces con respecto al debate clasicismo-romanticismo.

\subsection{Federico de Madrazo (1815-1894) y Eugenio de Ochoa (1815-1872)}

De la trayectoria biográfica de los fundadores de El Renacimiento, ambos de gran importancia en el ámbito de la pintura y la literatura, respectivamente, ya hablamos al ocuparnos de la evolución del rotativo, por lo que no nos detendremos de nuevo en ello. Sí nos parece necesario recordar una vez más que en el momento en que se pusieron al frente de la empresa los ánimos de estos dos autores habían cambiado notablemente con respecto a la época de El Artista, de ahí que sus opiniones respecto a las Bellas Artes, en concreto la arquitectura, resulten muy conservadoras. Por otra parte, el hecho de que nos refiramos a las contribuciones de ambos a este campo concreto en el mismo apartado se debe a que consistieron, en su mayoría, en notas aparecidas en las últimas páginas de la revista a nombre de la redacción, expresando, por lo tanto, el sentir de ambos directores.

Como comprobaremos al analizar los artículos de los demás autores, estos eran de una extensión mucho menor, algo lógico teniendo en cuenta que solían estar incluidos en secciones dedicadas a varios temas distintos $y$, como era 
habitual en ellas, solamente se extendían durante dos o tres párrafos. Por otra parte, no contenían disquisiciones sobre la evolución de los estilos artísticos, la encrucijada en que se encontraba la arquitectura española a mediados del siglo XIX o el debate entre clasicismo y medievalismo, sino la opinión personal de Madrazo y Ochoa acerca de cuestiones concretas que les habían dado que pensar durante sus paseos por la capital. El tono de estas notas breves era por lo general bastante despectivo, pues no en vano pretendían servir como denuncia a una serie de "desmanes arquitectónicos» sobre los que los autores querían hacer reflexionar.

De estos textos deducimos que ambos se encontraban en 1847 muy apegados a la tradición, dado que no dudaron en cargar las tintas contra los jóvenes arquitectos que estaban llevando a cabo actuaciones demasiado modernas y atrevidas, especialmente en cuanto a la ruptura con los cánones clasicistas que, como también comprobaremos en los siguientes apartados de nuestro estudio, no eran tan sacrosantos para otros redactores de El Renacimiento. Sirva como ejemplo la siguiente nota aparecida el 11 de abril de 1847, en la sección titulada «República de artes y letras», sobre unos edificios que acababan de construirse en Madrid y que a Madrazo y Ochoa les parecían ridículos. Nótense las alusiones al teatro clásico, un detalle que delata, en nuestra opinión, la autoría de Ochoa.

Cunde el mal gusto con una celeridad digna un hipódromo. Los arquitectos, lanzados á la carrera, rivalizan entre sí por completar en el menor tiempo posible el círculo de las aberraciones. El autor de una casa muy conocida, que sin duda ha estudiado la arquitectura por Sófocles, ha imaginado el modo de hacer que su fábrica inspire los sentimientos de la tragedia: terror y compasión. Ha quitado al cornisamento de las pilastras del cuerpo principal, el arquitrabe, que era lo que racionalmente debia sostener sus diversas partes, de manera que en la apariencia dicho cornisamento deberia desplomarse si no estuviera embutido en el edificio. Todas las puertas de la planta baja de la fachada presentan una paradoja semejante: sus dovelas, perfectamente rectangulares, amenazan con sumo chiste aplastar al que pase por debajo de ellas. Pero el público debe tranquilizarse, porque el autor de la obra, con un esfuerzo de ingenio digno de mejor causa, ha sabido hacer que dichas dovelas tengan por la parte interior la construccion que deben tener para sostenerse; de modo que está averiguado que para él es principio de buen gusto el que una cosa parezca lo contrario de lo que debe lógicamente ser (Madrazo y Ochoa, 11 de abril de 1847, p. 40).

«¿Cuándo se persuadirán los artistas», concluían los autores, "de que la verdad es el primer precepto del buen gusto?» (Madrazo y Ochoa, 11 de abril de 1847, p. 40). En esto se encuentra presente una de las críticas más recurrentes entre quienes consideraban en época isabelina, como era el caso de Ochoa y Madrazo, que la arquitectura que se estaba realizando por entonces carecía de sinceridad, debido a la tendencia de los jóvenes técnicos a lo artificioso y excesivo. 
El mismo tono crítico se aprecia en otras notas de similares características en las que ya no se ponían en tela de juicio desmanes arquitectónicos sino intervenciones de carácter decorativo en edificios anteriores, cuestión que de nuevo revela el recelo de los autores que nos ocupan ante ciertas prácticas que se estaban llevando a cabo por aquel entonces. Una vez más, la mentalidad tradicional de Ochoa y Madrazo en cuanto a lo arquitectónico les llevó a indignarse ante la costumbre de enlucir las fachadas y los muros con colores vistosos, costumbre a la que ellos se refirieron sarcásticamente como "hermosear». De ahí que en una nota aparecida en la revista el 25 de abril de 1847 anunciaran que acababan de colocarse unos andamios en la calle de Atocha para revocar la fachada de la Casa de los Cinco Gremios Mayores, convertida en dicho año en el nuevo Banco Español de San Fernando, añadiendo a renglón seguido: «No dejaremos de volver por alli dentro de algunos días para saber con que color ha sido embestida dicha casa, que por cierto es dígna de buena suerte tanto por su buen aspecto como por su ocupación» (Madrazo y Ochoa, 25 de abril de 1847, p. 56). Este empleo tan irónico de la letra cursiva vuelve a estar presente en otra nota de similares características, publicada el 27 de junio de 1847, en la que Madrazo y Ochoa se hacían eco de cómo se había hermoseado la fachada de la parroquia de Santa María y se preveía hacer lo propio con la de San Luis, lo cual les llevó a dar un consejo a los artífices de la obra en cuestión: «[Recomendamos] á los revocadores que subiesen un poco de tono las tiras de color de mahon para que luzcan todavía mas si cabe.... aunque por otra parte (ya se nos iba olvidando) lo mejor es enemigo de lo bueno» (Madrazo y Ochoa, 27 de junio de 1847, p. 128).

Paralelamente, Madrazo publicó un artículo más extenso el 28 de marzo de 1847, titulado "Algunas palabras sobre ornato público», en el que de nuevo se lamentaba de la costumbre de "pintarrajear las fachadas de las casas con colorines chillones» (Madrazo, 28 de marzo de 1847, 19). En este texto se aprecia más claramente que no era la arquitectura contemporánea en sí lo que disgustaba al codirector de El Renacimiento, pues de hecho alababa mucho la obra que estaba realizando Narciso Pascual Colomer (1808-1870) en el Palacio de las Cortes, sino la tendencia a enmascarar lo arquitectónico con «los colores de rosa, amarillo, morado, azul celeste y otros, más ó menos modestamente descarados» (Madrazo, 28 de marzo de 1847, p. 20). Por otra parte, afirmaba:

Y no se crea que somos de los que quieren que se practique esclusivamente esta ó aquella arquitectura: ¡lejos de nosotros tal idea! que aunque tengamos gusto propio y aficion á alguna de ellas en particular, estamos persuadidos de que no debe ser esto de mero capricho, sino de exigencia de las necesidades de nuestra sociedad, y de los materiales con que se pueda contar en cada pais. Ni tampoco criticaremos, como consecuencia de lo que acabamos de decir, á los que emplean con preferencia la griega, la árabe ó la del renacimiento, y si se quiere la de Churriguera; pero quisiéramos que lo que se haga tenga carácter, que pertenezca a una arquitectura, á una época, sin que por esto entendamos que por copiar literalmente una época, se desatiendan las exigencias 
hijas de los usos de nuestro siglo; lo demás lo combatiremos, porque detestamos las arlequinadas en las obras de arte (Madrazo, 28 de marzo de 1847, pp. 20-21).

Consciente de que su punto de vista era conservador al expresarse así, Madrazo se veía en la necesidad de asegurar que no veía problema alguno en que los arquitectos se inspiraran en estilos que no tuvieran nada que ver con lo clásico, aunque recomendaba no mezclar en la misma obra elementos tomados de épocas distintas. Este rechazo a lo que más adelante sería recurrente en los edificios de estilo ecléctico no se encontraba presente, como veremos más adelante, en el caso de otros autores como Antonio de Zabaleta, para quien precisamente el Eclecticismo era la mejor solución a estas diatribas.

\subsection{Pedro de Madrazo (1816-1898)}

Este autor fue uno de los más prolíficos en la prensa artística, colaborando durante todo el reinado isabelino con numerosas revistas en las que publicó artículos relativos a la cuestión artística. Hermano de Federico de Madrazo y perteneciente, por lo tanto, al poderoso clan familiar, se decantó en su caso por el estudio de la historia y la crítica de arte después de haber cursado la carrera de Derecho, que le llevó de hecho a formar parte del Consejo Real desde 1845. Fue miembro asimismo de otras instituciones como la Real Academia de Nobles Artes de San Fernando, en la cual desempeñó el cargo de director desde 1894 hasta 1898, la Real Academia de la Historia, en la que actuó como secretario entre 1879 y 1898, la Real Academia de la Lengua Española, en la que fue elegido miembro en 1881, y el Museo de Arte Moderno de Madrid, del que también fue director entre 1895 y 1898 . Como podemos observar, su carrera investigadora estuvo sembrada de galardones y reconocimientos que hicieron de Pedro de Madrazo no solo un erudito a ojos de la sociedad madrileña, sino un personaje de gran respetabilidad (Salas Vázquez, 2012, pp. 590-593; Pasamar Alzuria y Peiró Martín, 2002, pp. 374-376; Calvo Serraller, 1985, pp. 67-80).

En nuestro caso nos centraremos en sus trabajos de investigación sobre la cuestión artística, que abarcaban temas tan variados como el estudio de estilos arquitectónicos concretos, el estado de la arqueología en la segunda mitad de la centuria, la necesidad de que la sociedad interviniera más activamente en la defensa del patrimonio, la razón de ser de la crítica literaria y artística... Conviene tener en cuenta que, aunque gran parte de sus impresiones al respecto vieran la luz en la prensa artística, con la que ya hemos dicho que tuvo siempre mucha relación (llegó de hecho a ser uno de los miembros fundadores de El Artista junto con su hermano y su cuñado), la mentalidad de Pedro de Madrazo es notablemente distinta si comparamos esos artículos con las monografías que publicó sobre temas concretos. Esto se debe principalmente a que la mayoría de sus contribuciones en revistas como No Me Olvides, La llustración Artística, La llustración de Madrid o 
Museo Español de Antigüedades, o El Renacimiento del que nosotros nos ocupamos, datan de una época temprana, en la que su mentalidad todavía se hallaba imbuida del espíritu romántico, mientras que en esos estudios más sesudos y adultos poseía un posicionamiento mucho más positivista y científico que, al mismo tiempo, lo acercaba más a los historicismos, pues en ellos Pedro de Madrazo demostraba valorar todos los estilos artísticos con independencia de sus preferencias personales.

Esto resulta apreciable en obras tan dispares como Catálogo Descriptivo e Histórico del Museo del Prado de Madrid (incompleto, cuya primera parte publicó en 1872), Joyas sueltas del Arte Antiguo y Moderno (1874), Orfebrería de la época visigoda. Coronas y Cruces del Tesoro de Guarrazar (1879), Vidas de pintores célebres (1880) o La pintura mural de los templos (1883). Todas estas aportaciones, posteriores al período isabelino, hicieron de él una figura clave en los inicios de la historiografía artística de nuestro país, sumadas a su pertenencia a las instituciones ya mencionadas.

Pero centrémonos en los artículos que publicó en El Renacimiento. Al ser muy anteriores a estos estudios que acabamos de citar, no resulta extraño que en ellos esté presente todavía ese influjo romántico que, no obstante, no cegó a Pedro de Madrazo tanto como a otros jóvenes de su generación fascinados por el arte medieval. Si bien su punto de vista al respecto es más admirativo que el de su hermano, para quien hemos comprobado que la tradición clasicista poseía un gran peso, observamos que lo más encomiable que este encontraba en la arquitectura gótica era el espíritu que la animaba.

En efecto, en los cuatro artículos de Pedro de Madrazo que vieron la luz en esta revista («Bellas Artes. Consideraciones generales sobre su Renacimiento» el 21 de marzo de 1847, "Bellas Artes. Génesis del arte cristiano» el 28 de marzo de 1847, "Bellas Artes. Sobre una de las causas de la decadencia del arte antiguo» el 18 de abril de 1847 y «Bellas Artes. Del primer renacimiento de las artes y la literatura» el 27 de junio y el 4 de julio de 1847) el historiador hacía hincapié en un mismo tema: la contraposición entre la arquitectura grecorromana y la gótica, y entre la gótica y la renacentista. En su opinión, el arte pagano había producido la mayor belleza posible en el orden de las ideas "finitas» mientras que el cristiano había abierto los ojos al cielo para alcanzar las «infinitas». Este tour de force entre la Antigüedad y la Edad Media, en la que espiritualmente salía ganando esta última según Madrazo, demuestra hasta qué punto estaba arraigada en España una de las principales ideas acuñadas en el siglo XIX con respecto a la Edad Media: la de que su arte encarnaba mejor que ningún otro el auténtico cristianismo y, en consecuencia, debía ser tomado como inspiración en una época en la que la religiosidad se había convertido en una cuestión de enorme interés.

La decadencia de los griegos y los romanos se había producido, según él, por la ausencia de una fuente moral a la hora de llevar a cabo sus creaciones. No bastaría con limitarse a copiar la realidad; habría que tratar de insuflarle el hálito de la 
divinidad, lo que sí se había conseguido hacer por el contrario en la Edad Media. Según Madrazo:

Las artes que solo habian servido para recrear al hombre, fueron destinadas á moralizarle, á ennoblecer sus instintos, á purificar y elevar sus aspiraciones, á enseñarle por fin con símbolos palpables al sentido, verdades morales hasta entonces ignoradas, verdades necesarias para su salvacion, que el pueblo no puede comprender sino bajo una forma tangible, que consuelan al pobre labrador en sus fatigas, al poderoso magnate en las penas de su ambicion (Madrazo, 28 de marzo de 1847, p. 18).

Ahora bien, si la arquitectura grecorromana era según Madrazo superior a la gótica en cuanto a su forma, y la gótica superior a la grecorromana en cuanto a su aliento, la desarrollada en el Renacimiento era para él superior a ambas, precisamente porque reunía sus dos principales virtudes. De ahí que dedicara esos cuatro artículos a hablar de su origen y evolución, siempre teniendo en cuenta que no podría haberse desarrollado sin haber pasado antes por la Edad Media que durante siglos había sido denostada por artistas y eruditos por considerarla una época «bárbara». Madrazo era por el contrario de la opinión de que, si la mentalidad de los hombres no hubiera cambiado como lo hizo en ese período, habría sido muy peligroso tratar de retomar la herencia de Grecia y Roma, pues se habría corrido el riesgo de caer una vez más en el paganismo.

La seductora forma antigua debia permanecer oculta mientras se completase el desarrollo del nuevo espíritu: desarrollo penoso que duró trece siglos, en cuyo tiempo se estuvo fortificando la inteligencia humana, y preparándose para sobrellevar sumisa la belleza sin atreverse bárbaramente á profanarla. La antigüedad habia apurado todas las manifestaciones estéticas; la edad media fiel tambien á su tarea, apuró todas las especulaciones religiosas; y asi como trajo la providencia á la humanidad á este nuevo camino, cuando la sociedad antigua no podia ya dar mas de si sin caer en las aberraciones, del mismo modo, cuando la edad media habia agotado la fuente vivificadora de la meditacion sobre la vida eterna, cuando ya no podia la razon producir nada útil en el campo de las abstracciones sin estraviarse en el peligroso vacío adonde se lanzó el atrevido cisne de Wittemberg, hizo la misma providencia que la resurreccion de la belleza que yacía olvidada, diese cuerpo al pensamiento religioso, y asegurase su dominio entre los hombres con indestructibles cimientos (Madrazo, 28 de marzo de 1847, p. 18).

Como hemos dicho, conforme pasaron los años Pedro de Madrazo se acercó de manera progresiva a un mayor positivismo que le hizo dar una menor importancia, pero sin llegar a abandonarla del todo, a su idea de que la doctrina cristiana había sido la piedra de toque que cambió por completo el panorama de la arquitectura europea a partir del siglo XV. En los estudios posteriores de los que ya hemos 
hablado dejó a un lado el Renacimiento para centrarse en los estilos medievales (ocupándose incluso de algunos que por entonces apenas habían sido abordados, como el visigodo), siendo el gótico, nuevamente, el que más le interesaba. Esto queda patente en su respuesta al discurso de recepción en la Real Academia de Nobles Artes de San Fernando en 1868 de José Escrivà de Romaní, marqués de Monistrol (1825-1890), que llevaba el significativo título de La influencia del cristianismo en la arquitectura de los siglos medios y que el arte ojival es esencialmente cristiano y en el que, siempre en aras de la apertura a los historicismos que se estaba produciendo en esa época, se recomendaba a los arquitectos contemporáneos tomar como inspiración lo que se había llevado a cabo en las grandes catedrales góticas por constituir una perfecta plasmación de la España cristiana.

\subsection{Antonio de Zabaleta (1803-1864)}

El caso de Zabaleta se diferencia de los anteriores en el hecho de que no se trataba de un escritor, un crítico o un pintor hablando de arquitectura, sino de un técnico que conocía el oficio de primera mano y poseía, además, unas ideas muy claras en cuanto a su sentido y un conocimiento profundo de las elucubraciones que se estaban llevando a cabo en Francia al respecto, ya que al igual que Madrazo y Ochoa tuvo la oportunidad de estudiar en París. Perteneciente a una familia acomodada, se comprometió desde su juventud con el movimiento liberal y fue considerado un "romántico militante», con un aperturismo de mente que se encuentra muy presente en sus colaboraciones en la prensa artística de la época. Fue precisamente esa implicación con la doctrina liberal lo que le condujo al exilio en 1823 coincidiendo con el fin del Trienio Liberal; fue entonces cuando se instaló en París, asistiendo en persona al debate europeo entre los arquitectos que seguían manteniéndose fieles al corpus clasicista, generalmente de edad madura y apegados a la tradición, y los jóvenes románticos que apostaban por una ruptura con los presupuestos que hasta entonces se habían tenido por sacrosantos. Tras estudiar en la Université de la Sorbonne y formarse como arquitecto en el estudio de Félix Duban (1798-1870), se trasladó a Italia con una pensión concedida por la Real Academia de Nobles Artes de San Fernando para continuar con sus estudios, lo que le permitió entrar en contacto con restos romanos que estaban excavándose por aquel entonces en zonas como la Magna Grecia. Finalmente regresó a España en 1837, siendo nombrado al año siguiente vicepresidente de la sección de Arquitectura del Liceo Artístico y Literario y empezando a impartir clase ocho años después en la Escuela Especial de Arquitectura (Sazatornil, 1992, p. 37; Sazatornil, 2014, p. 122; Navascués, 1993, p. 23).

Estos avatares biográficos de Zabaleta nos parecen de una gran importancia para comprender por qué se posicionó como lo hizo en sus artículos sobre arquitectura. No en vano se le considera no solo uno de los profesores más notables 
de la escuela que acabamos de mentar, sino uno de los responsables, junto con el también arquitecto Aníbal Álvarez Bouquel (1806-1870), de la renovación de la enseñanza que se llevó a cabo desde mediados de la centuria decimonónica en dicho centro (Prieto, 2004, 35). Esencialmente, los profesores de la escuela se mantuvieron en la estela de sus predecesores franceses de mentalidad más adelantada al perseguir un equilibrio entre la formación artística y la científica, así como una defensa de la libertad de los arquitectos que hasta entonces, por esa dictadura de lo clasicista, se habían visto obligados a no emplear más que cinco órdenes constructivos que limitaban notablemente su capacidad creativa. Mediante esa ruptura con la hegemonía grecorromana se comenzó a abrir en España la puerta a unos historicismos (neogótico, neorrenacimiento, neomudéjar, etc.) que acabarían triunfando en las siguientes décadas, algo que en el caso concreto de Zabaleta resulta apreciable tanto en sus proyectos arquitectónicos como en sus contribuciones en la prensa artística (García Melero, 2002, p. 171).

En efecto, algunos de los artículos de este autor causaron cierta polémica cuando salieron a la luz por defender con absoluto convencimiento unas teorías que por aquel entonces eran aceptadas en el extranjero, pero que en España no se habían escuchado jamás. El ejemplo más paradigmático es un texto titulado "Arquitectura» que apareció en dos partes en No Me Olvides en julio de 1837, coincidiendo con el regreso del joven Zabaleta a España tras su estancia en Italia. Además de mostrar ya un aperturismo con respecto a estilos arquitectónicos que en esa época aún no eran admirados, afirmó sin ambages que la arquitectura griega había sido polícroma, algo que había observado personalmente en esas excavaciones en la Magna Grecia a las que ya hemos dicho que asistió pero que en España, que en esas fechas todavía seguía estando poderosamente apegada a los postulados del Neoclasicismo, fue considerado casi sacrílego. Asimismo, cabe mencionar que Zabaleta fue fundador de una revista, el mentado Boletín Español de Arquitectura, del que solo vieron la luz trece entregas en 1846 y que poseía un tono mucho más técnico que las revistas artísticas orientadas por entonces al gran público.

En lo concerniente a su colaboración con El Renacimiento, fue muy estrecha desde el principio. Ya en la introducción del primer número Madrazo y Ochoa anunciaban que se habían asociado con los redactores del recientemente desaparecido Boletín Español de Arquitectura, «con quienes nos liga una perfecta conformidad de principios», para poder alcanzar entre todos la meta de «difundir en España las sanas doctrinas artísticas y literarias y dar entre nosotros al arte y á los que le cultivan la noble é importante posición que reclaman en una sociedad bien organizada» (Madrazo, 14 de marzo de 1847, p. 3). No obstante, conviene que tengamos presente que esa "perfecta conformidad de principios» no fue óbice para que Zabaleta hiciera gala en sus artículos en El Renacimiento de una mentalidad mucho más avanzada que los Madrazo, concretamente que Federico, de talante más conservador. 
El único texto que publicó en la revista que nos ocupa vio la luz en el número del 14 del marzo de 1847 con el elocuente título de "Bellas Artes. Arquitectura. Aplicacion del arte antiguo al arte moderno -Sistemas opuestos- La Academia, la Escuela gótica, y los eclécticos en Francia». Como era de esperar, en este artículo Zabaleta vertió sus opiniones respecto a esos debates que se habían producido diez años antes en el país vecino entre los arquitectos que apostaban por la impronta clasicista y los que hacían lo propio con la apertura a otros estilos, debates a los que había podido asistir en su momento y con los que de nuevo entró en contacto cuando en 1846, un año antes, viajó de nuevo a París para adquirir grabados franceses que pretendía incluir en el Boletín.

Al analizar las opiniones expresadas por ambos bandos, y también por aquellos a los que denomina "eclécticos» y cuya mentalidad compartió en sus propios proyectos, el arquitecto acabó llegando a la conclusión de que todos tenían la misma preocupación: la supuesta falta de originalidad de la arquitectura del siglo XIX y la ausencia de fuentes de inspiración que no hicieran caer en un anacronismo continuo al imitarlas. No hay que dejar de tener presente que, en el fondo, esa misma indefinición que tanto angustiaba a los arquitectos de la España isabelina acabó conduciéndoles a un pluralismo que hoy en día pasa por ser uno de sus rasgos definidores, pese a que ellos no lo consideraran una muestra de su personalidad sino precisamente de lo contrario: la carencia de la misma (Navascués, 1993, p. 32).

En su artículo, Zabaleta lanzaba la siguiente pregunta: «¿Puede pedirse á nuestro siglo una arquitectura que le sea propia, esto es, un sistema de construccion enteramente nuevo, especial, individual, y que se distinga de los que le han precedido?» (Zabaleta, 14 de marzo de 1847, p. 3). Él mismo afirmaba a renglón seguido que no, ya que en su opinión «la arquitectura es un arte que reproduce con demasiada exactitud el estado de las costumbres y de la sociedad», lo que hacía imposible que en el siglo XIX, "época de indiferentismo, época sin creencias de ninguna especie», pudiera surgir de repente "una creacion dotada de tales caracteres y de tal vida, que logre personificar lo que realmente no existe" (Zabaleta, 14 de marzo de 1847, p. 3). Eso le llevó a afirmar que lo peor que podían hacer los arquitectos era obcecarse siguiendo al pie de la letra las máximas clasicistas, al igual que afirmaba que podía sucederles a los que hicieran lo propio con las del recientemente redescubierto gótico. Para él, la solución a ese estado de indefinición era aprender de lo que se había realizado en todos los siglos y todos los estilos, a fin de incorporar aquellos elementos que resultaran convenientes y que fueran susceptibles de ser aunados en un mismo edificio sin que este pareciera "un conjunto monstruoso compuesto de informes amalgamas» (Zabaleta, 14 de marzo de 1847, p. 4). Es una apuesta, por tanto, por la doctrina ecléctica, aunque siempre desde un punto de vista científico, sensato y racional: 
Estudiemos pues todos los estilos y las obras maestras de todas las edades, y de todas las naciones; pero tengamos muy presente que el primer elemento de belleza, es la conveniencia, esto es, la relacion armoniosa del edificio con su destino especial y con todas las condiciones que le imponen su situacion, la naturaleza del clima y el estado de la civilizacion á que pertenece; tomemos despues (como ya hemos dicho) al crear un edificio los caracteres generales de solo tal ó cual gran familia de monumentos, modifiquemos el tipo que de entre ellos hayamos escojido, imprimámosle un carácter particular y apropiémosle en lugar de copiarle.- Hé aquí nuestro modo de pensar relativamente á la aplicacion de la arquitectura antigua al arte de nuestros dias.- Vemos pues que no excluimos ni el griego, ni el romano, ni el bizantino, ni el llamado gótico, ni el del renacimiento; y que si bien creemos que pudiera darse la preferencia al último por estar mas en armonía con nuestros usos y conveniencias actuales, nos abstenemos de decir, por ahora, cosa alguna sobre este punto (Zabaleta, 14 de marzo de 1847, p. 5).

"Las reglas en arquitectura», seguía diciendo Zabaleta, "no son mas absolutas ni mas imperativas que en las demas artes», y añadía más tarde que "en ella la inspiracion y el sentimiento ordenan: la escuadra y el compas obedecen " (Zabaleta, 14 de marzo de 1847, p. 5). En relación con esto, Zabaleta se mostraba lógicamente menos despreciativo que otros autores en cuanto a las modificaciones que los arquitectos modernos realizaban sobre los órdenes clásicos. En su opinión no tenía sentido que se consideraran unos preceptos inmutables, dado que ese carácter de perdurabilidad probablemente no existió desde el principio, sino que fue cobrando forma con el paso de los siglos. Sobre este tema Zabaleta se mostraba tajante:

Pero guardémonos de creer que no tenemos mas que cinco maneras de proporcionar un edificio, y que fuera de estos cinco órdenes, como se los llama, no encontrarémos mas que error y barbárie. Si Vitrubio hubiera visto y medido mayor número de monumentos, hubiera multiplicado estraordinariamente sus órdenes, ó mas bien no hubiera dado sino como medios aproximativos lo que, bajo su palabra, se ha tomado por reglas absolutas. En efecto: ya hemos probado en el núm. 5. del Boletin Español de arquitectura que los antiguos no sujetaban su arquitectura á proporciones fijas y determinadas, como pretende dicho autor, y como aun se cree, queriendo por este medio reducir este arte liberal á otro mecánico, y creyendo que es mas docto Arquitecto el que tiene mas en la memoria las reglas de Vignola y cuanto mas las de Palladio (Zabaleta, 14 de marzo de 1847, pp. 5-6).

Nótese que esta ruptura con la consideración de que los cinco órdenes clásicos eran las únicas opciones con las que contaban los arquitectos es lo mismo que Zabaleta llevó a cabo en el sistema de enseñanza de la Escuela Especial de Arquitectura. «El tener un molde único, por decirlo así, donde deban fundirse las ideas del arte», seguía afirmando en este artículo, "es un principio de muerte para él mismo; es convertirlo en un miserable oficio» (Zabaleta, 14 de marzo de 1847, p. 6). Una apuesta decidida por el Eclecticismo que coincide con lo que el propio arquitecto puso en práctica en sus proyectos y que, como adelantamos al hablar 
de Federico de Madrazo, se aparta notablemente de la mentalidad de autores más conservadores, que rechazaban hacer de los edificios una amalgama de estilos distintos.

\subsection{Francesc Pi i Margall (1824-1901)}

Como hemos dicho, este autor es el más avanzado en cuanto a su mentalidad entre los que abordaron la cuestión arquitectónica en El Renacimiento. La implicación de Pi i Margall en la política del momento, especialmente a partir de la caída de Isabel II, es sobradamente conocida, así como su relación con el movimiento de la Renaixença que aspiraba a hacer «renacer» la lengua y la cultura catalanas después de siglos de diglosia con respecto al castellano. Miembro del recientemente fundado Partido Demócrata desde 1849, diputado en las Cortes Constituyentes por la circunscripción de Barcelona en 1869 y presidente durante poco más de un mes de la Primera República Española, su posicionamiento condicionó enormemente sus opiniones sobre los estilos artísticos (Vilches, 2013, pp. 472-477; Miguel, 2006, pp. 93-108).

De ellas queda constancia en obras como los dos tomos de Recuerdos y Bellezas de España publicados en 1848 y 1858 acerca de Cataluña, Asturias, Castilla la Nueva, Granada, Almería y Jaén, amén de estudios independientes como La España Pintoresca (1841), Historia de la Pintura (1850-1852), obra que fue censurada por el gobierno de Juan Bravo Murillo (1803-1873) por su planteamiento de contestación religiosa, y sobre todo Estudios de la Edad Media (1851). Aunque esta última realmente no vería la luz hasta 1873 , una gran parte de los planteamientos de Pi i Margall expresados en la prensa artística isabelina sobre las construcciones góticas se encuentra presente en ella.

En relación con la mentalidad de la Renaixença de la que hemos hablado antes, su fascinación eminentemente romántica por este período de la arquitectura española se debió a que pasó a ser considerado una evocación de los tiempos medievales además de una plasmación perfecta de la religiosidad cristiana, una idea que, como hemos visto, se encuentra presente también en los artículos sobre Bellas Artes de Pedro de Madrazo. A estas circunstancias se sumaron las particularidades que había alcanzado el gótico de la Corona de Aragón en el siglo XIV, otorgando a los edificios erigidos en este territorio unas características perfectamente reconocibles y distinguibles de las de los castellanos que, como es lógico, despertaron el interés de los catalanes de mentalidad nacionalista.

Por lo tanto, no resulta extraño que en los artículos publicados por Pi i Margall en El Renacimiento, como uno titulado "Una ojeada a la historia del arte monumental» que vio la luz en dos partes el 2 y el 9 de mayo de 1847, rompiera una lanza desde el primer momento por la arquitectura de la Edad Media con una pasión que, en su caso, no nacía simplemente del fervor romántico, sino también 
de esas connotaciones nacionalistas que poseían las construcciones góticas para los catalanes. "La Europa ha vuelto los ojos á la edad media», afirmaba en este texto; "deseosa de sondar las ideas que dominaron en estos doce siglos, ha recogido con avidez sus manuscritos, recorridos los capiteles de sus claustros, examinado las pinturas de sus altares..." (Pi i Margall, 2 de mayo de 1847, p. 58). Más adelante Pi i Margall se deshacía en elogios hacia las catedrales góticas, entonando una alabanza similar a la que podemos encontrar en escritos de Victor Hugo (18021885) o Théophile Gautier (1811-1872), en los cuales ambos solían hacer hincapié en puntos similares a los del autor que nos ocupa: el sentido ascensional de este estilo, rasgo derivado de su vinculación con el cristianismo, y el carácter orgánico que hacía de estos edificios auténticos microcosmos.

Fijense ahora los ojos sobre estas bellas catedrales góticas que cubren el mundo cristiano, los mas grandes poemas sin duda que creó la edad media, aun sin esceptuar los de Dante y de Aristo, tan místicos y caprichosos como aquellos; pásense los ojos sobre estas creaciones inmensas, producto de la piedad, de la constancia y de la inteligencia de generaciones enteras, álbum en que cada hombre del pueblo viene á escribir sus mejores concepciones, depósito sagrado en que cada cual viene á espaciar sus sentimientos, hoja de agravios por fin en que todos vienen á fijar sus quejas, y digásenos si no se distingue donde quiera la libertad del pueblo, la victoria de las artes, la profundidad de sentimientos religiosos. Sus fachadas son como vallas levantadas entre el mundo de los cuerpos y el mundo de los espíritus. Apenas penetramos en el interior, la religion se apodera de nosotros y nos hace doblar la frente y la rodilla ante sus misteriosos altares. Sus cimborios y sus torres elevan nuestras miradas y nuestras preces hácia el templo de los cielos. Cuando pasada la primera impresion, nos entregamos al minucioso exámen de sus detalles, vemos en todas partes un mundo de figuras de santos, de reyes, de soldados, de frailes, de monstruos á veces, caricaturas quizás de los personajes de la epoca; admiramos lo bello de la composicion, lo delicado de la ejecucion (Pi i Margall, 9 de mayo de 1847, p. 67).

En relación con este convencimiento absoluto por parte de Pi i Margall de que las construcciones góticas merecían un puesto de honor en la Historia del Arte español, se encuentran otras ideas de nuevo relacionadas con su aperturismo de mente que le hacen aproximarse a lo esgrimido por Antonio de Zabaleta en el artículo del que ya nos hemos hecho eco anteriormente. En efecto, Pi i Margall también consideraba que había llegado el momento de romper con la tiranía tradicionalmente ejercida por lo grecorromano en el ámbito artístico, apostando por una diversidad mucho mayor de estilos a la hora de escoger una fuente de inspiración para la arquitectura decimonónica. En su opinión, el triunfo del positivismo (más en el extranjero que en España por entonces) era la causa de que se estuvieran investigando con un mayor rigor estilos anteriormente despreciados: 
Hechos estos estudios con tan feliz éxito, la historia del arte ha pretendido ensanchar el campo de sus investigaciones. Ha sospechado que la arquitectura de otras épocas y de otros países podía ofrecer iguales resultados; y de aquí ese movimiento contínuo, ese afan de correr el mundo y analizar detenidamente desde los monumentos colosales de la India y del Egipto hasta las piedras aisladas de los Celtas. Donde quiera ha reconocido la influencia de nuevas generaciones, las luchas de las revoluciones sociales y políticas, el sello de los imperios. Ha hecho luego tales comparaciones, y han sido tales sus resultados, que no ha dudado en sentar: que la historia monumental del mundo marcha al paso de la historia del género humano ( $\mathrm{Pi}$ i Margall, 2 de mayo de 1847, pp. 58-59).

Esta defensa enconada de los historicismos llevó a Pi i Margall a interesarse en sus demás artículos por estilos que hasta entonces apenas se habían tocado en estas revistas. Es el caso de uno titulado «Arquitectura egipcia» aparecido el 4 de julio de 1847 , en el que la compara con la india atendiendo al condicionamiento ejercido por el medio, la religión y la política de cada civilización, un planteamiento que también se encontraba presente en el artículo anterior y que acerca a Pi i Margall a los postulados de Georg Wilhelm Friedrich Hegel (1770-1831) y, aunque posterior, también a los de Jacob Burckhardt (1818-1897) (Pi i Margall, 4 de julio de 1847, pp. 131-134). Esta idea vuelve a estar presente en otro artículo sobre la arquitectura india aparecido en dos partes entre mayo y junio (Pi i Margall, 30 de mayo de 1847, pp. 89-91; Pi i Margall, 6 de junio de 1847, pp. 97-99). Obviamente, de todos estos estilos hasta entonces, por así decirlo, marginados entre los redactores de las revistas isabelinas, el que Pi i Margall consideraba que debía servir como inspiración a los jóvenes arquitectos decimonónicos era el gótico, principalmente por una cuestión de mayor proximidad tanto cronológica como geográfica y cultural.

\section{CONCLUSIONES}

El análisis de las aportaciones de cada uno de estos autores nos ha permitido llegar a unas conclusiones muy claras con respecto al papel desempeñado por El Renacimiento en el debate entre clasicismo y romanticismo. En primer lugar, conviene tener en cuenta en todo momento que esta revista se caracterizó por una notable permisividad hacia sus redactores en cuanto a la difusión de sus propias ideas. Si bien la mentalidad de Ochoa y Madrazo como directores era de talante conservador en cuanto a lo artístico, ello no les impidió dejar que Pedro de Madrazo, Antonio de Zabaleta y Francesc Pi i Margall se explayaran acerca de sus puntos de vista pese a que no coincidieran con los de ambos.

También hemos podido comprobar que había razones de peso detrás de la elección de uno u otro posicionamiento por parte de estos autores. Mientras que Eugenio de Ochoa y Federico de Madrazo se encontraban perfectamente asentados 
en la sociedad burguesa del Madrid isabelino, Pedro de Madrazo mostró su mentalidad cada vez más positivista al comenzar a interesarse por estilos artísticos hasta entonces ignorados, Antonio de Zabaleta expresó en sus escritos las mismas ideas que puso en práctica en su producción arquitectónica y Francesc Pi i Margall se dejó llevar por su pasión por una Edad Media que la Renaixença estaba convirtiendo en una oriflama del pasado catalán.

Esta disparidad de criterios, en el fondo, no hace sino confirmar la personalidad anacrónica de El Renacimiento, pese a lo mucho que se interesó por la situación de las Bellas Artes en esa época y ese contexto concretos. En efecto, además de tratarse de una revista con características de la década de 1830 pero aparecida en 1847, poseía una diversidad de puntos de vista en cuanto a la cuestión de la que nos hemos ocupado que hizo de ella un rotativo poliédrico, conservador en las manos que sostenían sus riendas, pero moderno en las opiniones de algunos de sus redactores. En definitiva, lo que demuestra esta circunstancia es que El Renacimiento resultaba de difícil definición precisamente porque mostraba, quizás mejor que ninguna otra revista de su época, la situación de confusión en que se encontraba España en materia arquitectónica y la preocupación de unos artistas que no dejaban de preguntarse, como también quedó plasmado en estos artículos, si serían capaces algún día de emular a sus predecesores.

\section{REFERENCIAS BIBLIOGRÁFICAS}

Ayala Aracil, M. de los Á. (2002). La defensa de lo romántico en la revista literaria El Artista. En VV. AA., Los románticos teorizan sobre sí mismos (pp. 35-42). Bolonia: Il Capitello del Sole.

Blanco Martín, M. Á. (1987). Opinión pública y libertad de prensa (1808-1868). En Varios autores. La prensa española durante el siglo XIX. I Jornadas de especialistas en prensa regional y local (pp. 27-52). Granada: Instituto de Estudios Almerienses, Granada.

Calvo Serraller, F. (1985). Pedro de Madrazo, historiador y crítico de arte. En Varios autores. Los Madrazo, una familia de artistas (pp. 67-80). Madrid: Museo Municipal.

Calvo Serraller, F. y González García, Á. (1981). Estudio preliminar. En Varios autores. El Artista (edición facsímil), I. Madrid: Turner.

García Castañeda, S. (1979). Miguel de los Santos Álvarez. Romanticismo y poesía. Madrid: SGEL. 
García Melero, J. E. (2002). Literatura española sobre artes plásticas. Madrid: Encuentro.

Henares Cuéllar, I. y Calatrava, J. (1982). Romanticismo y teoría del arte en España. Madrid: Cátedra.

Isac, Á. (1987). Eclecticismo y pensamiento arquitectónico: discursos, revistas, congresos. 1846-1918. Granada: Diputación Provincial de Granada.

Lafuente Ferrari, E. (1987). Breve historia de la pintura española. Madrid: Akal.

López Sanz, G. E. (2000). Romanticismo frente a clasicismo en El Artista (1835-1836). Espéculo. Revista de estudios literarios, 14 (sin páginas). Recuperado el 13 de junio de 2016, de http://www.ucm.es/info/especulo/numero14/artista1.html

Madrazo, F. de (28 de marzo de 1847). República de artes y letras. El Renacimiento, 3, p. 19.

Madrazo, F. de y Ochoa. E. de (11 de abril de 1847). República de artes y letras. El Renacimiento, 5, p. 40.

Madrazo, F. de y Ochoa. E. de (14 de marzo de 1847). Introducción. El Renacimiento, 1, p. 3.

Madrazo, F. de y Ochoa. E. de (25 de abril de 1847). República de artes y letras. El Renacimiento, 7, p. 56.

Madrazo, F. de y Ochoa. E. de (27 de junio de 1847). República de artes y letras. El Renacimiento, 16, p. 128.

Madrazo, P. de (18 de abril de 1847). Bellas Artes. Sobre una de las causas de la decadencia del arte antiguo. El Renacimiento, 6, pp. 41-43.

Madrazo, P. de (21 de marzo de 1847). Bellas Artes. Consideraciones generales sobre su Renacimiento. El Renacimiento, 2, pp. 9-10.

Madrazo, P. de (27 de junio de 1847). Bellas Artes. Del primer renacimiento de las artes y la literatura. El Renacimiento, 16, pp. 121-123.

Madrazo, P. de (28 de marzo de 1847). Bellas Artes. Génesis del arte cristiano. El Renacimiento, 3, pp. 17-18. 
Madrazo, P. de (4 de julio de 1847). Bellas Artes. Del primer renacimiento de las artes y la literatura. El Renacimiento, 17, pp. 129-131.

Miguel González, R. (2006). Francisco Pi i Margall (1824-1901): La construcción de la Democracia republicana socialista y de la Legalidad democrática españolas. En VV. AA., Figuras de la Gloriosa. Aproximación biográfica al Sexenio Democrático (93-108). Valladolid: Secretariado de Publicaciones de la Universidad de Valladolid.

Navascués Palacio, P. (1993). Arquitectura española 1808-1914. Summa Artis, XXXV. Madrid: Espasa-Calpe.

Pasamar Alzuria, G. y Peiró Martín, I. (2002). Diccionario Akal de Historiadores españoles contemporáneos. Madrid: Akal.

Pi i Margall, F. (2 de mayo de 1847). Una ojeada a la historia del arte monumental. El Renacimiento, 8, pp. 58-59.

Pi i Margall, F. (30 de mayo de 1847). Arquitectura india. El Renacimiento, 12, pp. 89-91.

Pi i Margall, F. (4 de julio de 1847). Arquitectura egipcia. El Renacimiento, 17, pp. 131-134.

Pi i Margall, F. (6 de junio de 1847). Arquitectura india (Continuación). El Renacimiento, 17, pp. 97-99.

Pi i Margall, F. (9 de mayo de 1847). Una ojeada a la historia del arte monumental (Continuación). El Renacimiento, 9, pp. 66-67.

Prieto González, J. M. (2004). Aprendiendo a ser arquitectos: creación y desarrollo de la Escuela de Arquitectura de Madrid (1844-1914). Madrid: Ediciones del Consejo Superior de Investigaciones Científicas (CSIC).

Rodríguez Gutiérrez, B. (2014). El Artista arrepentido: El Renacimiento de 1847. Voz y letra: Revista de literatura, 15(1), 77-98.

Salas Vázquez, E. (2012). Madrazo y Kuntz, Pedro de. En Varios autores, Diccionario Biográfico Español, XXI (pp. 590-593). Madrid: Real Academia de la Historia.

Sazatornil Ruiz, L. (1992). Antonio de Zabaleta: la renovación romántica de la arquitectura española. Madrid: Ediciones Tantín. 
Sazatornil Ruiz, L. (2014). Arte o técnica. Arquitectos españoles entre Roma y París (1830-1851). En Varios autores, El arte español entre Roma y París (siglos XVIII y XIX). Intercambios artísticos y circulación de modelos (pp. 103-128). Madrid: Casa de Velázquez.

Torres Nebrera, G. (2012). Ochoa y Montel, Eugenio. En Varios autores, Diccionario Biográfico Español, XXXVIII (pp. 241-243). Madrid: Real Academia de la Historia.

Vilches García, J. (2013). Pi i Margall, Francisco. En VV. AA., Diccionario Biográfico Español, XLI (pp. 472-477). Madrid: Real Academia de la Historia.

Zabaleta, A. de (14 de marzo de 1847). Bellas Artes. Arquitectura. Aplicacion del arte antiguo al arte moderno. El Renacimiento, 1, pp. 3-6. 